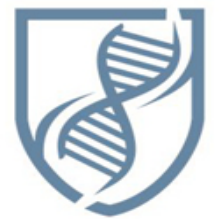

Journal of Bioscience and Applied Research
JBAAR

WWW.JBAAR.ORG

\title{
Clomiphene citrate induced kidney injury in female albino rat
}

\author{
Hawazen A. Lamfon ${ }^{1}$ and Nahid A. Lamfon ${ }^{2}$ \\ ${ }^{1}$ Biology Department, Faculty of Applied Science, Umm Al- Qura University, Makkah, Saudi Arabia \\ 2 Consultant Family \&Community Medicine, King Abullaziz medical City / National Guard \\ Health Affair / Riyadh \\ Corresponding author E-mail: halamf@uqu.edu.sa
}

\begin{abstract}
Clomiphene citrate (clomid), a selective oestrogen-receptor modulator, is used in the treatment of polycystic ovary syndrome. On the other hand, it showed many adverse effects. The present work investigates the effects of clomiphene citrate $(\mathrm{CC})$ on kidney of female albino rats. Many biochemical and histological changes were induced in these animals when treated with $\mathrm{CC}$ at doses of 50 and $100 \mathrm{mg} / \mathrm{kg}$ body weight. Treating animals with doses of 50 and $100 \mathrm{mg} / \mathrm{kg}$ body weight caused elevations in serum creatinine and urea. The histological changes in the kidney of treated animals included intertubular leucocytic infiltrations, congestion of blood vessels and degeneration of renal tubules. Moreover, atrophy of glomeruli was recorded. In conclusion, biochemical and histopathological alterations indicated that clomiphene citrate causes renal damage in female albino rats.
\end{abstract}

Keywords: Biochemistry, Clomiphene citrate, Histology, Kidney, Rats.

\section{Introduction}

Clomiphene citrate (CC), a selective oestrogen-receptor modulator, used for treatment for infertile women ( $\mathrm{Abu}$ Hashim, 2012). It works to induce ovulation by inhibiting negative, endogenous, oestrogen-feedback on the hypothalamic-pituitary axis, resulting in increased FSH secretion, follicular growth, and ovulation (Emily et al., 2010). On the other hand, uses of clomiphene citrate was accompanied with many adverse effects, such as ovarian enlargement, vasomotor flashes, nausea, vomiting, breast discomfort, headache, abnormal vaginal bleeding, visual symptoms, weight gain and shortness of breath (Sherbahn,2015). Keskin et al., (2007), reported that CC induced acute pancreatitis. It also caused myocardial infarction (Duran and Raja, 2007), hypertriglyceridemia (Yasar and Ertugrul, 2009), deep vein thrombosis (Benshushan et al., 1995) and pulmonary embolism (Chamberlain and Cumming, 1986). Nagao and Yoshimura (2001) reported that Clomiphene citrate has been shown to cause ovarian and uterine abnormalities. The association between birth defects, e.g. neural tube defects, hypospadias and uses of CC was reported by some investigators (Sorensen et al., 2005; Meijer et al., 2006). Reefhuis et al. (2011) have identified associations between the use of clomiphene citrate and anencephaly, Dandy Walker malformation, septal heart defects, muscular VSD, coarctation of the aorta, esophageal atresia, cloacal exstrophy, craniosynostosis and omphalocele. Shimono et al. (1998) have reported that women who took CC suffered from ovarian hyperstimulation syndrome complicated by hepatic injury. Al-Amoudi (2012) reported that CC induced histological and biochemical alterations in liver of rats. The present work was conducted to evaluate the nephrotoxicity of $\mathrm{CC}$ in female albino rats.

\section{Materials and Methods}

\section{Experimental animals}

Adult female Albino rats with an average weight of $160 \pm$ $10 \mathrm{~g}$ were used in the present study. The animals were placed in plastic cages (ten animals per cage) at room temperature $\left(22 \pm 2{ }^{\circ} \mathrm{C}\right)$ and relative humidity $40-65 \%$. The animals were kept in alternating light and dark 
conditions for 12 -hour periods. The rats were maintained on commercial food consisting of standard rat chow. Rat food pellets were purchased from the Saudi Grain Oils and Floor Mills organization, Jeddah, Saudi Arabia. Rats had free access to drinking water. All animals received care in accordance with the methods approved under the institutional guidelines for the care and use of laboratory animals. The animals were divided into three groups; each group consisted of 15 rats.

Group 1: The rats of this group were considered as controls.

Group 2: The rats of this group were given daily with 50 $\mathrm{mg}$ of clomid/kg body weight for two weeks.

Group 3: The rats of this group were fed daily with 100 $\mathrm{mg}$ of clomid/ $\mathrm{kg}$ body weight for two weeks.

Clomiphene citrate (clomid) is an nonsteroidal, ovulatory stimulant designated chemically as 2-[p-(2-chloro-1,2diphenylvinyl) phenoxy] triethylamine citrate . Clomiphene citrate was obtained from King Abullaziz medical City / National Guard, Health Affair / Riyadh. A stock solution of clomiphene citrate was prepared by dissolving clomiphene citrate in distilled water. Each concentration of clomid was given to the rats orally by intragastric intubation.

\section{Histological study}

The treated animals and their controls were killed by cervical dislocation, quickly dissected and kidney was removed, fixed in Bouin's fluid. After $24 \mathrm{~h}$, tissues were rinsed three times in $70 \%$ ethanol, dehydrated using a graded ethanol series and then embedded in paraffin wax. Paraffin sections were cut into 5 micrometers thick slices and stained with haematoxylin and eosin and examined under light microscope.

\section{Biochemical study}

For biochemical assays, blood samples were collected from animals after the end of the experiment. Sera were obtained by centrifugation of the blood sample and stored at $-20^{\circ} \mathrm{C}$. Urea and creatinine were measured using a fully automated Hitachi 911 analyzer (Tokyo, Japan). A commercial randox kits (Randox Laboratories, LTD, Ardomre, Crumlin, United Kingdom) were used in these analysis.

\section{Statistical analysis}

The results were expressed as mean \pm SD of different groups. The differences between the mean values were evaluated by ANOVA followed by Student's "t" test using Minitab 12 computer program (Minitab Inc., State Collage, P.A).

\section{Results}

\section{Histological observations}

Examination of kidney cortex sections of control rats showed normal renal tubules and renal corpuscles. The bowman capsule and the glomeruli appeared to be prominent (Fig.1). Treating animals with clomid at a dose level of $50 \mathrm{mg} / \mathrm{kg}$ b.w. revealed many histological alterations. The renal veins were enlarged and congested with blood and the renal tubules showed wide lumen and separation of the epithelial cells from its membrane (Fig.2). The intertubular spaces were field with leucocytic infiltrations (Fig.3). Such alterations became severe in animals given clomid at a dose level of $100 \mathrm{mg} / \mathrm{kg}$ b.w. Distortion of the renal architecture and atrophy of glomeruli was observed. The epithelial lining of the renal tubules were degenerated and showed cytoplasmic vacuolization as well as pyknosis of the nuclei (Fig.4).

Leucocytic inflammatory cells were spread in large areas of the intertubular tissue (Fig.4). Large edematous spaces were observed (Fig.5).

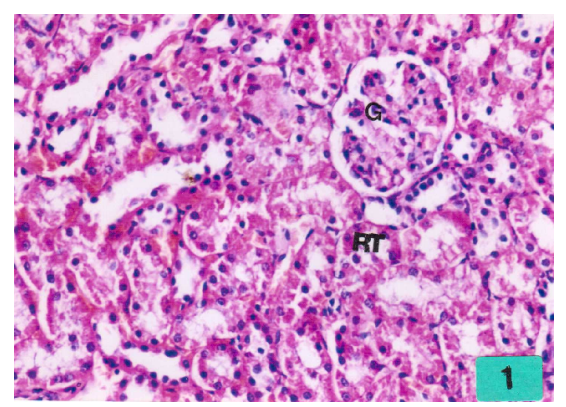

Fig.1. Section of kidney of a control rat showing the glomerulus (G) and renal tubules (RT) X 400.

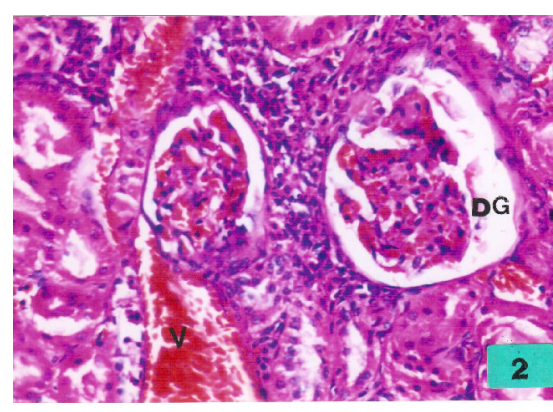

Fig.2. Section of kidney of a rat treated with $50 \mathrm{mg} / \mathrm{kg}$ b.w. clomiphene citrate showing congested blood vessels (v) and degenerated glomerulus (DG), X 400.

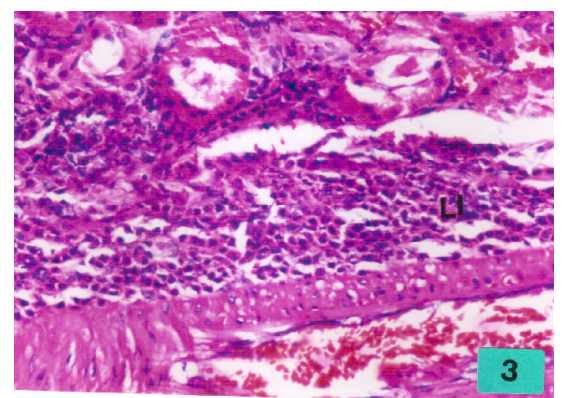

Fig. 3. Section of kidney of a rat treated with $50 \mathrm{mg} / \mathrm{kg}$ b.w. clomiphene citrate showing Leucocytic infiltration (LI) $\mathrm{X} 400$. 


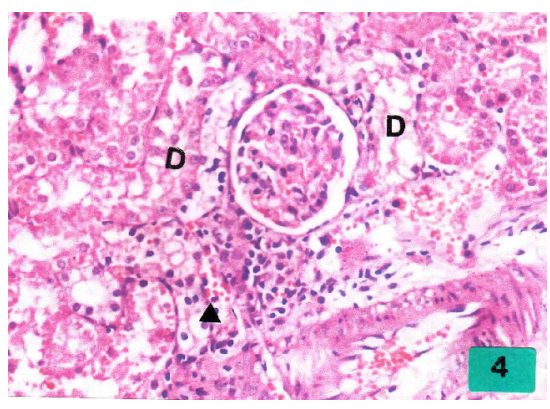

Fig.4. Section of kidney of a rat treated with $100 \mathrm{mg} / \mathrm{kg}$ b.w. clomiphene citrate showing damaged tubules (D) with cytoplasmic vacuolation of linning epithelium (arrow head) $\mathrm{X} 400$.

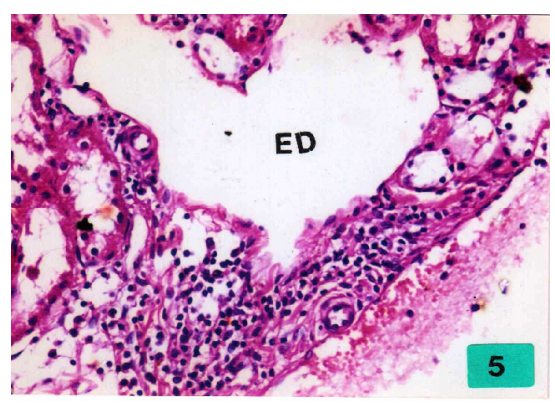

Fig. 5. Section of kidney of a rat treated with $100 \mathrm{mg} / \mathrm{kg}$ b.w clomiphene citrate showing large demotes space(ED) X400.

\section{Biochemical results}

Treating animals with clomiphene citrate at the doses 50 and $100 \mathrm{mg} / \mathrm{kg}$ b.w. caused a highly significant elevation $(\mathrm{P}<0.05)$ in the level of serum creatinine, and urea as compared to those of the control animals (Figs.6\&7).

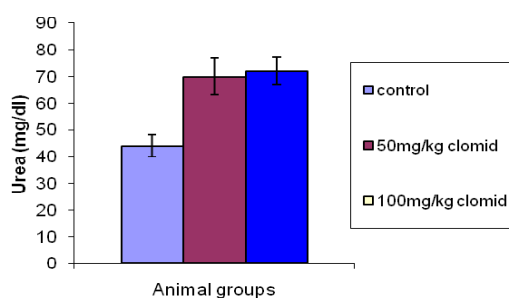

Fig. 6. Effect of different doses of clomid on urea

\section{Discussion}

Clomiphene citrate has been demonstrated to be a useful therapy for the anovulatory patient desiring pregnancy.The first endocrine event in response to a course of clomiphene therapy is an increase in the release of pituitary gonadotropins. This initiates steroidogenesis and folliculogenesis, resulting in growth of the ovarian follicle and an increase in the circulating level of estradiol.
Following ovulation, plasma progesterone and estradiol rise and fall as they would in a normal ovulatory cycle (Emily et al., 2010).

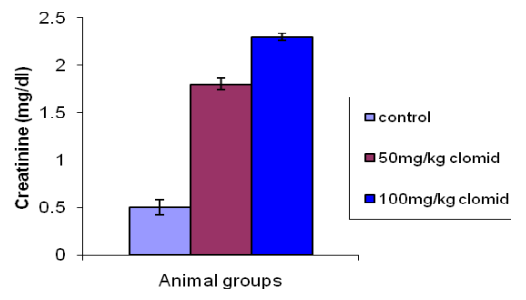

Fig. 7. Effect of different doses of clomid on creatinine

The present results showed that clomid caused many histological alterations in kidney of female rats. It also caused elevation in creatinine and urea, the indicative of kidney dysfunction. The kidneys are organs in which there are estrogen receptors spread at the level of their structures that have important modulating effects on complex metabolic and functional processes that take place both in glomeruli and in the tubular interstitial area. Mesangial cells contain both ER $\alpha$ and ER $\beta$ (Potier et al.2001). Ovariectomy (ovx) of Dahl salt sensitive rats (DS) caused decreases in ER $\alpha$ but increases in ER $\beta$ expression in the renal cortex and medulla, whereas ovx in Dahl salt resistant (DR) rats caused decreases in cortical and increases in medullary ER $\alpha$, and increases in ER $\beta$. In addition, estradiol replacement returned ER $\beta$ expression to preovx levels in both DS and DR, but had no effect on ER $\alpha$ (Esqueda et al. 2007). Insight from in vitro studies and animal models suggest that sex steroids play pivotal roles in modifying the progression to kidney diseases. The effect of estrogens on kidney was studied by some investigators. Administration of estradiol to Ovariectomy Zucker rats impaired renal function further and led to profound glomerulosclerosis (Stevenson et al.2000). Zhan et al. (2008) showed that moderate and high doses of $17 \beta$-estradiol not only increased mortality and deteriorated cardiac remodeling and function but also caused kidney and liver damage as evidenced by severe hydronephrosis, liver enlargement and ascites. Gades et al.(1998) reported that in diabetic animals, $17 \beta$-estradiol increases plasma creatinine and triglyceriderich lipoproteins, and it has been suggested that their binding to glomerular cells initiates or accelerates glomerulosclerosis.In addition to glomerular injury, $17 \beta$ estradiol also caused urine retention, tubular dilatation, hydronephrosis, and hydroureter, mostly at high doses (Pearse et al.2009). Meng et al. (2011) reported that $17 \beta$ estradiol reduced renal function as evidenced by hydronephrosis, tubular dilatation and increased glomerular matrix deposition as well as increased plasma creatinine and albuminuria. Silbiger and Neugarten (2008) reported that sex hormones may directly influence many processes involved in the pathogenesis of renal diseases progression. They consider that several mechanisms could be involved: 
receptor-mediated effects of sex hormones on glomerular haemodynamics and mesangial cell proliferation, matrix mesangial proliferation, effects on the synthesis and release of cytokines, vasoactive agents and growth factors, alteration in the renin-angiotensin system, reduction in mesangial collagen synthesis, the modification of collagen degradation and up-regulation of nitric oxide synthesis.Estrogens can be metabolically activated into catechol estrogens by cytochrome P450 enzymes. Metabolic redox cycling between catechol estrogens and their corresponding quinones generates oxidative stress and potentially harmful free radicals (Lieher et al.1986). Wellejus and Loft (2002) suggested that oxidative effect could be receptor mediated. It could be that catechol estrogen bound to the estrogen receptor is transported to estrogen-sensitive genes in the nucle-us, where redox cycling may take place. It is concluded from the result of the present work that Clomiphene citrate induced kidney injury via its oxidative stress.

\section{Acknowledgment}

Authors would like to thank Sabic company- Saudia Arabia and Institute of Consulting Research and Study (IRCS) Umm- AlQura University, KSA, for funding this work (grant NO 0058/01/30).

\section{References}

Abu Hashim H. (2012). Clomiphene citrate alternatives for the initial management of polycystic ovary syndrome: an evidence-based approach. Arch. Gynecol. Obstet., 285(6):1737-1745.

Al-Amoudi, W.M. (2012). Biochemical and Histological Effects of Clomiphene Citrate on Liver of Female Albino Rat. J. Am. Sci., 8(5): 646-651.

Benshushan A, Shushan A, Paltiel O, Mordel N, Laufer N (1995). Ovulation induction with clomiphene citrate complicated by deep vein thrombosis. Eur. J. Obstet. Gynecol. Reprod. Biol., 62(2):261-262.

Chamberlain R.A and Cumming D.C (1986). Pulmonary embolism during clomiphene therapy for infertility in a male: a case report. Int. J. Fertil., 31(3):198199.

Duran, J.R. and Raja, M.L. (2007). Myocardial infarction in pregnancy associated with clomiphene citrate for ovulation induction: a case report. J. Reprod. Med., 52(11):1059-62.

Emily, S. Jungheim, M.D, Anthony O. Odibo, M.D. (2010). Fertility treatment in women with polycystic ovary syndrome: a decision analysis of different oral ovulation induction agents. Fertil. Steril. 94(7):2659-2664.

Esqueda, M.E., Craig, T., Hinojosa-Laborde, C. (2007). Effect of ovariectomy on renal estrogen receptor alpha and estrogen receptor beta in young salt-sensitive and -resistant rats. Hypertension, 50 (4):768-772.
Gades, M.D., Stern, J.S., van Goor, H., Nguyen, D., Johnson, P.R. and Kaysen, G.A. (1998). Estrogen accelerates the development of renal disease in female obese Zucker rats. Kidney Int., 53 (1):130-135.

Keskin, M., Songür, Y. and Isler, M. (2007). Clomiphene-induced acute pancreatitis without hypertriglyceridemia. Am. J. Med. Sci., 333(3):194-196.

Liehr, J. G., Ulubelen, A. A. and Strobel, H. W. (1986). Cytochrome P-450-mediated redox cycling of estrogens. J. Biol. Chem., 261:16865-16870.

Meijer, W.M., de Jong-Van den Berg, L.T., van den Berg, M.D., Verheij, J.B. and de Walle, H.E. (2006). Clomiphene and hypospadias on a detailed level: signal or chance? Birth Defects Res. A Clin. Mol. Teratol., 76(4):249-252.

Meng, X., Dai, X., Liao, T. D., D’Ambrosio, M., Wang, F., Yang, J.J. and Yang, X.P. (2011). Dosedependent toxic effects of high-dose estrogen on renal and cardiac injury in surgically postmenopausal mice. Life Sci., 88(3-4): 178-186.

Nagao, T. and Yoshimura, S. (2001). Oral administration of clomiphene to neonatal rats causes reproductive tract abnormalities. Teratog. Carcinog. Mutagen., 21(3):213-221.

Pearse, G., Frith, J., Randall, K.J. and Klinowska, T. (2009). Urinary retention and cystitis associated with subcutaneous estradiol pellets in female nude mice. Toxicol. Pathol., 37 (2):227-234.

Potier, M., Elliot, S.J., Tack, I., Lenz, O., Striker, G.E., Striker, L.J. and Karl, M. (2001). Expression and regulation of estrogen receptors in mesangial cells: influence on matrix metalloproteinase-9. J. Am. Soc. Nephrol., 12: 241251.

Reefhuis, J., Honein, M.A., Schieve, L.A. and Rasmussen, S.A. (2011). Use of clomiphene citrate and birth defects. Hum. Reprod., 26(2):451-457.

Shimono, J., Tsuji, H., Azuma, K., Hashiguchi, M. and Fujishima, M. (1998). A rare case of hepatic injury associated with ovarian hyperstimulation syndrome. Am. J. Gastroenterol., 93(1):123-124.

Sherbahn, R. (2015).Side effects and adverse effects of clomid, clomiphene citrate. Advanced Fertility Center of Chicago, USA.

Silbiger, S. and Neugarten, J. (2008). Gender and human chronic renal disease. Gend. Med. 5A: S3-S10.

Sorensen, H.T., Pedersen, L., Skriver, M.V., Norgaard, M., Norgard, B. and Hatch, E.E. (2005). Use of clomifene during early pregnancy and risk of hypospadias: population based casecontrol study. BMJ. 330(7483): 126-127.

Stevenson, F.T., Wheeldon, C.M., Gades, M.D., Kaysen, G.A., Stern, J.S. and van Goor, H. (2000). Estrogen worsens incipient hypertriglyceridemic glomerular injury in the obese Zucker rat. Kidney Int., 57: 1927-1935. 
Yasar, H.Y. and Ertugrul, O. (2009). Clomiphene citrate-induced severe hypertriglyceridemia. Fertil. Steril., 92(1):396.e7-8.

Wellejus, A. and Loft, S. (2002). Receptor-mediated ethinylestra-diol-induced oxidative DNA damage in rat testicular cells. FASEB J.,16: 195-201.

Zhan, E., Keimig, T., Xu, J., Peterson, E., Ding, J., Wang, F. and Yang, X.P. (2008). Dose-dependent cardiac effect of oestrogen replacement in mice post-myocardial infarction. Exp. Physiol., 93 (8): 982-993. 